\title{
Air vs rail competition towards the Beijing-Shanghai high-speed railway project in China
}

\author{
Junjie Mao*t \\ Civil Aviation Development Research Institute of CAAC, Jia No. 24, \\ Xibahe Beili, Chaoyang District, Beijing, 100028, China
}

\begin{abstract}
China's railway has launched an ambitious speed-up program, the Beijing-Shanghai High-speed Railway project, which challenges the civil aviation industry aggressively. This paper studies the current air-rail competition pattern considering passenger throughput, transport time, ticket fare and economic growth, and furthermore, uses the Logit Model to forecast the future competition situation between civil aviation and railway along the Beijing-Shanghai High-speed Railway areas. The study also offers proposals for civil aviation industry towards the challenges of the new railway project.
\end{abstract}

Key words: air-rail competition, civil aviation, high-speed railway, logit model, fare, time.

\section{I NTRODUCTION}

With its rapid development in civil aviation, China had become the second largest country in civil aviation in the world by 2005 and civil aviation is playing a more and more important role in China's national economy. In China's integrated transportation system involving railway,

\footnotetext{
* Junjie Mao graduated in engineering from Fudan University in China and subsequently gained a Master degree in European Policy Studies from the University of Bristol in the UK. He joined the Civil Aviation Development Research Institute of the Civil Aviation Administration of China in April 2004, where he has been involved in a number of major consultancy projects for civil aviation authorities, airplane manufacturers, airports and airlines. His research focuses on airport finance, regional aviation and airport system planning.

† E-mail : maojj@mail.castc.org.cn, phone:+86 13910096211, fax:+86 1064473631
} 
highway, water carriage and civil aviation, passenger turnover of Chinese civil aviation had increased to $13 \%$ in 2007 from $1.8 \%$ in 1979 and will increase to $20 \%$ in 2020 according to the goal of the Civil Aviation Administration of China (CAAC). Compared with it, the railway passenger turnover dropped from $61.7 \%$ in 1979 to $33.5 \%$ in 2007.

Typically, airlines carry more passengers traveling between Beijing and Shanghai than railway service providers in the competitions between them. The major problems for the railway administration are the deficient transportation capacity of railway service providers and the rising time effectiveness by passengers. That is why the Beijing-Shanghai high speed railway project, which claims up to US $\$ 30$ billion investment, with approval of Chinese government in 2007. The railway administration hopes that this ambitious project can improve the capacity of its transportation and that will pose a real challenge to the civil aviation. Therefore, the future competitive situation of passenger transportation between Beijing and Shanghai after the project receives a high concern for both administrations of the civil aviation and railway.

Firstly, this paper will analyze the current situation of passenger transportation for cities along the Beijing-Shanghai high-speed railway, and focus on the differences between the civil aviation and the railway services in passenger throughput, transport time and fares. Secondly, it will set up a competition model between civil aviation and railway in order to analyze the impact on their competitive situation if the high-speed railway is put into service. At last, it will put forward some workable countermeasures for the civil aviation to meet the challenges from the highspeed railway project.

\section{CURRENT COMPETTITION BETWEen THE CIVIL AVIATION AND RAILWAY SERVICE}

\section{1. OVERALL SITUATION}

On April 18, 2007, China put the sixth speed up of railways into effect, that it raised national train speeds from $160 \mathrm{~km}$ per hour to $200 \mathrm{~km}$ per hour. The former speed-up projects had been launched by the Ministry of Railways in 1996, 1998, 2000, 2001 and 2004. This ambitious speed up of railway poses a great challenge to the civil aviation along with improving services. Ever so 
the macro data still shows that, in passenger transportation service, the development in civil aviation is far beyond the railway service, which means that the civil aviation is on the rise while the railway service is reducing the shares in the integrated transportation system. The air passenger volume and turnover volume saw an average increase of $16.7 \%$ and $17.1 \%$ respectively between 2000 and 2007, while the rail passenger volume and turnover volume saw an average increase of only $5.2 \%$ and $7.7 \%$ respectively in the same period (See Table 1 ). According to the statistical data in China, it can be concluded that the former speed-up programs of railways had little impact on the rapid development of the civil aviation, especially in its passenger transportation service (See Fu 2005). It is noteworthy that the railway speed raising has some impact on the civil aviation transportation service in some specific routes, particularly for those short ones. Data also shows a rising trend in the average transportation distance of railway passengers and it proves that more mid-long range passengers are carried by railway. This lead to the growth of the average transportation distance of the civil aviation is less than the growth of the railway.

Table 1: Macro-analysis on passenger transportation volume in the railway service and the civil aviation

\begin{tabular}{cccccc}
\hline \multicolumn{5}{c}{ Railway Service } \\
\hline Year & $\begin{array}{c}\text { Passenger } \\
\text { volume } \\
(\text { million})\end{array}$ & $\begin{array}{c}\text { Increase } \\
\%\end{array}$ & $\begin{array}{c}\text { Passenger } \\
\text { Turnover } \\
(1 \text { billion } \\
\text { passenger km) }\end{array}$ & $\begin{array}{c}\text { increase } \\
\%\end{array}$ & $\begin{array}{c}\text { Average } \\
\text { distance } \\
(\mathrm{km})\end{array}$ \\
\hline 2000 & 1018 & - & 449 & - & 441 \\
\hline 2001 & 1052 & 0.1 & 478 & 5.2 & 454 \\
\hline 2002 & 1056 & 0.4 & 497 & 4.2 & 471 \\
\hline 2003 & 973 & -7.9 & 479 & -3.6 & 492 \\
\hline 2004 & 1118 & 14.9 & 571 & 19.3 & 511 \\
\hline 2005 & 1160 & 3.4 & 606 & 6.1 & 523 \\
\hline 2006 & 1260 & 8.7 & 662 & 9.2 & 526 \\
\hline 2007 & 1360 & 8.0 & 721 & 9.0 & 531 \\
\hline $\begin{array}{c}\text { Average } \\
\text { Increase }\end{array}$ & & 5.2 & & 7.7 & \\
\hline
\end{tabular}




\begin{tabular}{cccccc}
\hline \multicolumn{7}{c}{ Civil Aviation } \\
\hline Year & $\begin{array}{c}\text { Passenger } \\
\text { volume } \\
\text { (million) }\end{array}$ & $\begin{array}{c}\text { Increase } \\
\%\end{array}$ & $\begin{array}{c}\text { Passenger } \\
\text { Turnover } \\
(1 \text { billion } \\
\text { passenger km) }\end{array}$ & $\begin{array}{c}\text { increase } \\
\%\end{array}$ & $\begin{array}{c}\text { Average } \\
\text { distance } \\
(\mathrm{km})\end{array}$ \\
\hline 2000 & 67 & - & 100 & - & 1477 \\
\hline 2001 & 75 & 10.9 & 109 & 12.5 & 1447 \\
\hline 2002 & 86 & 15.4 & 127 & 16.2 & 1477 \\
\hline 2003 & 88 & 1.9 & 126 & -0.4 & 1442 \\
\hline 2004 & 121 & 38.4 & 178 & 41.1 & 1470 \\
\hline 2005 & 138 & 14.1 & 207 & 14.7 & 1479 \\
\hline 2006 & 160 & 15.4 & 237 & 15.9 & 1485 \\
\hline 2007 & 186 & 16.3 & 279 & 17.8 & 1503 \\
\hline $\begin{array}{l}\text { Average } \\
\text { Increase }\end{array}$ & & 16.7 & & 17.1 & \\
\hline
\end{tabular}

Source: National Statistics Bureau Website

\subsection{SITUATION OF PASSENGER TRANSPORTATION IN CITIES ALONG BEIJING- SHANGHAI HIGH-SPEED RAI LWAY}

Existed Beijing-Shanghai railway locates in eastern China, which is the most social-economic developed region with the most potential development. It runs through Beijing, Tianjin, Shanghai municipalities and four provinces of which are Hebei, Shandong, Anhui and Jiangsu. This region occupies only $6.5 \%$ of China's land area, but with $26.4 \%$ of the total population and 43.2\% of China's GDP in 2005. The per capita GDP of the region is 1.75 times of the national level.

Existed Beijing-Shanghai railway is the busiest railway trunk line in China, even in the world, which reaches $11.3 \%$ of the passenger turnover volume and $6 \%$ of the freight volume by only $2 \%$ of China's commercial railway mileage. And its transportation density is 4 times of the average in China. 
There are 10 civil airports distributing in the 8 cities of Beijing, Tianjin, Jinan, Xuzhou, Nanjing, Changzhou, Wuxi and Shanghai which along the Beijing-Shanghai railways, including some very busy airports. These 10 airports launched 12 air service in 2007 between Beijing and Shanghai, Beijing and Nanjing, Beijing and Changzhou, Beijing and Wuxi, Beijing and Xuzhou, Beijing and Jinan, Nanjing and Jinan, Nanjing and Tianjin, Jinan and Shanghai, Tianjin and Shanghai, Xuzhou and Shanghai and Tianjin and Wuxi. The passenger transport volume of these 12 routes is $5.58 \%$ of the total national passenger transport volume in 2007 and only the BeijingShanghai route has carried $3.44 \%$ of the total national passenger volume.

The present Beijing-Shanghai railway has been in a situation of tight transportation capacity, overload and limitations since 1990 and is unable to supply more transportation service. So the Chinese government decided to build the Beijing-Shanghai high-speed railway in order to solve these problems.

According to the master plan, the designed Beijing-Shanghai high-speed railway is $1,318 \mathrm{~km}$ long with 21 stations which passes through Beijing, Tianjin, Jinan, Nanjing and Shanghai. The total investment of this project is 220 billion RMB. It will be finished as early as 2010 with an initial cruise speed of $300 \mathrm{~km} / \mathrm{hr}$ which is slower than its designed speed, $350 \mathrm{~km} / \mathrm{hr}$. It implies that high-speed trains will take passengers between Beijing and Shanghai in only 5 hours, which replaced the fastest trains take people at least 9 hours between Beijing and Shanghai in present. After the high-speed railway project is completed and put into service, the separation of passengers and goods transportation will be realized between high-speed railway and present Beijing-Shanghai railway, in which the new built high-speed railway will be a special line for passengers only and the 'old' Beijing-Shanghai railway which is in used now will mainly service for freight. When the time comes, it will lift the one-way transport capacity to 80 million passengers and more than 130 million tonnes of cargo annually. Therefore, the project will relieve the tense transportation capacity in Beijing-Shanghai corridor and meet the future transportation demand.

\subsection{COMPARISON OF THE PASSENGER TRANSPORTATION IN CITIES ALONG THE LI NE BETWEEN THE CI VI L AVI ATI ON AND THE RAI LWAY SERVI CE}


This paper has a research on passenger transport service markets of 10 city pairs that both the civil aviation and railway service operated in 2000 and 2005. Total 11.62 million passengers traveled between these 10 city pairs in 2000 , of which $33.5 \%$ by air and $66.5 \%$ by train. However, total 17.85 million passengers traveled between these 10 city pairs in 2005, of which $39.8 \%$ by air and $60.2 \%$ by train. The railway did not gain more market share after the launching of the fifth speed-up, which reduced average 15\% runtime of trains between those 10 city pairs. Instead, more passengers traveled by air, because the increasing concern about travel time is always accompanying with the rapid national economic growth (see Figure 1).

Figure 1: Share of railway in 10 city-pair transport markets in 2000 and 2005

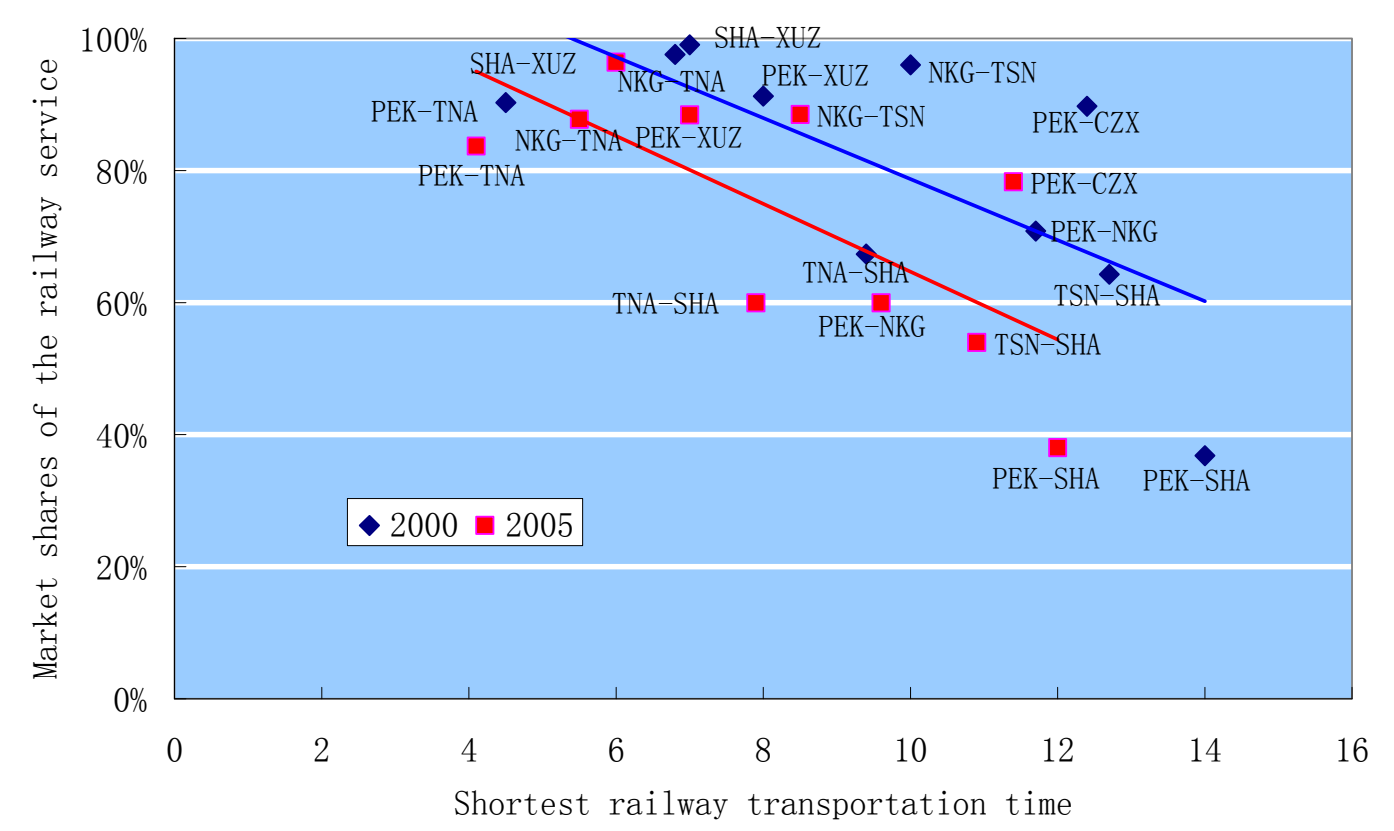

Source: CASTC.

It is mentionable that the passenger transport market of Beijing-Shanghai direct line was the only one which the civil aviation got a dominant position within these 10 city pairs, even though its market share dropped from $63 \%$ in 2000 to $62 \%$ in 2005. During the same period, in other 9 city pairs, the civil aviation gained more passenger market shares year by year. As far as in 2005, the number of passengers carried by all airlines between Tianjin-Shanghai, BeijingNanjing, Jinan-Shanghai increased as many as railway transportation. However, passengers 
traveling between other 6 city pairs still took priority of railway service, which was less than a quarter of the total passengers traveled by air.

The main advantage of the civil aviation is its transportation time when competing with the railway service. All of the transportation time of the 10 city pairs, civil aviation were less than One-fifth of that of railway service. However, more passengers trend to air travel with acceptable price due to the travel distance increasing, which implies the increase of time saved if they travel by air (see Figure 1 and Figure 2).

Figure 2: Comparison on transportation time between the civil aviation and the railway service in 10 city pairs

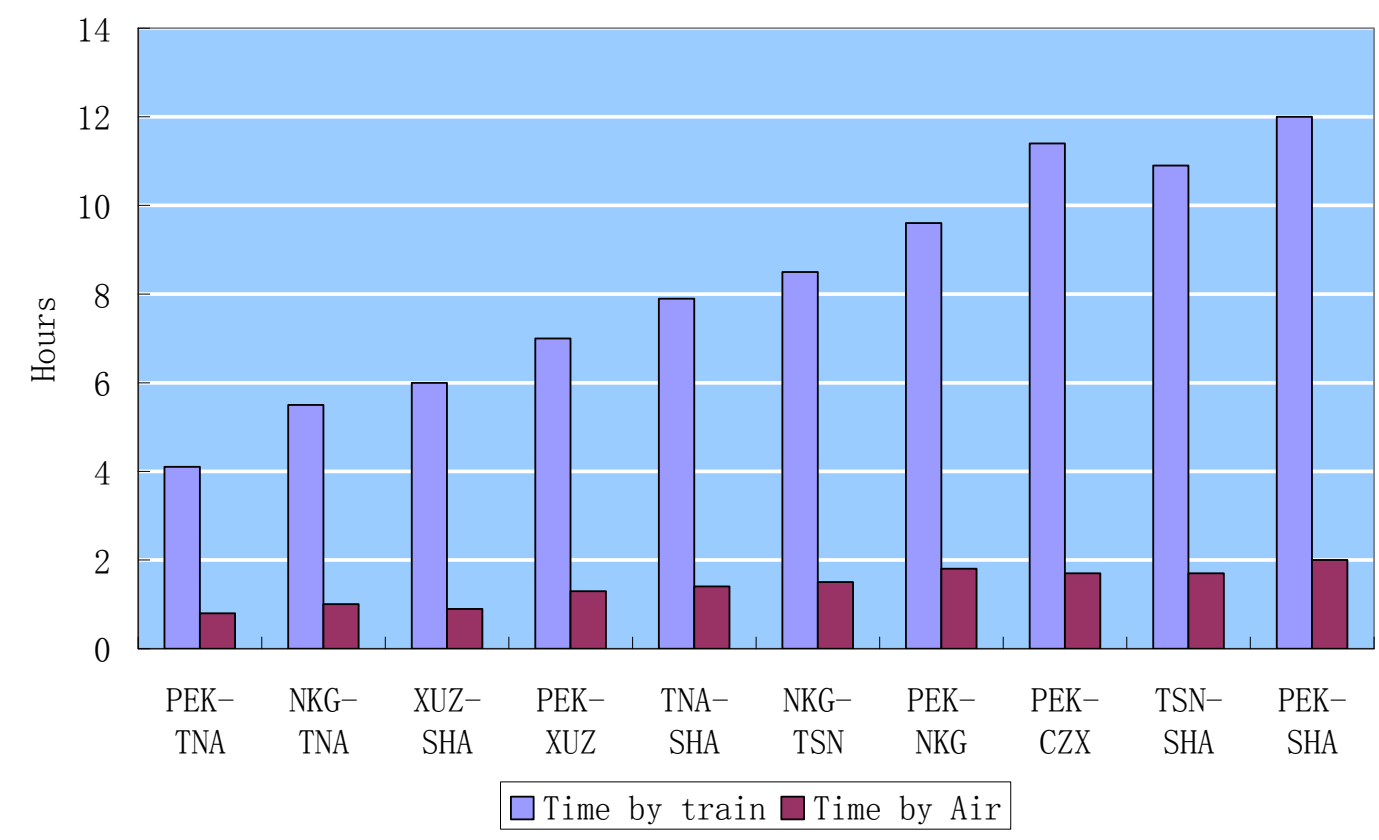

Source: CASTC.

The main disadvantage for the civil aviation is the fares when competing with the railway service. According to the benchmark airfares by the CAAC, the full price air fares are generally two times higher than that of the train tickets and even 3 times higher in Beijing-J inan and Nanjing-J inan routes. It deteriorates the airlines' disadvantages when competing with the railway service in short-distance transportation. But different from the fixed railway fare, airlines can offer flexible fares according to their marketing strategy goals because of the floating price 
mechanism applied. By measuring, the actual airfares are considerably lower than the benchmark fares published (see Figure 3).

It must be indicated that the passenger structures and their affordability remain huge differences between each city pair, because of uneven economic development between these cities, and this produces a large difference to passengers' susceptive prices and time. Because of relatively high per capita GDP, the passengers traveling between economic developed big cities are more time sensitivity and trend to travel by air. In the counterparts, passengers traveling between big cities and small-mid cities would rather travel by trains. Also, along with the development in national economy, passengers' sensibility to prices and time is changing, which is mentioned above that more passengers would like to pay more to save their time on the way.

Figure 3: Fares comparison between the civil aviation and the railway service in 10 city pairs

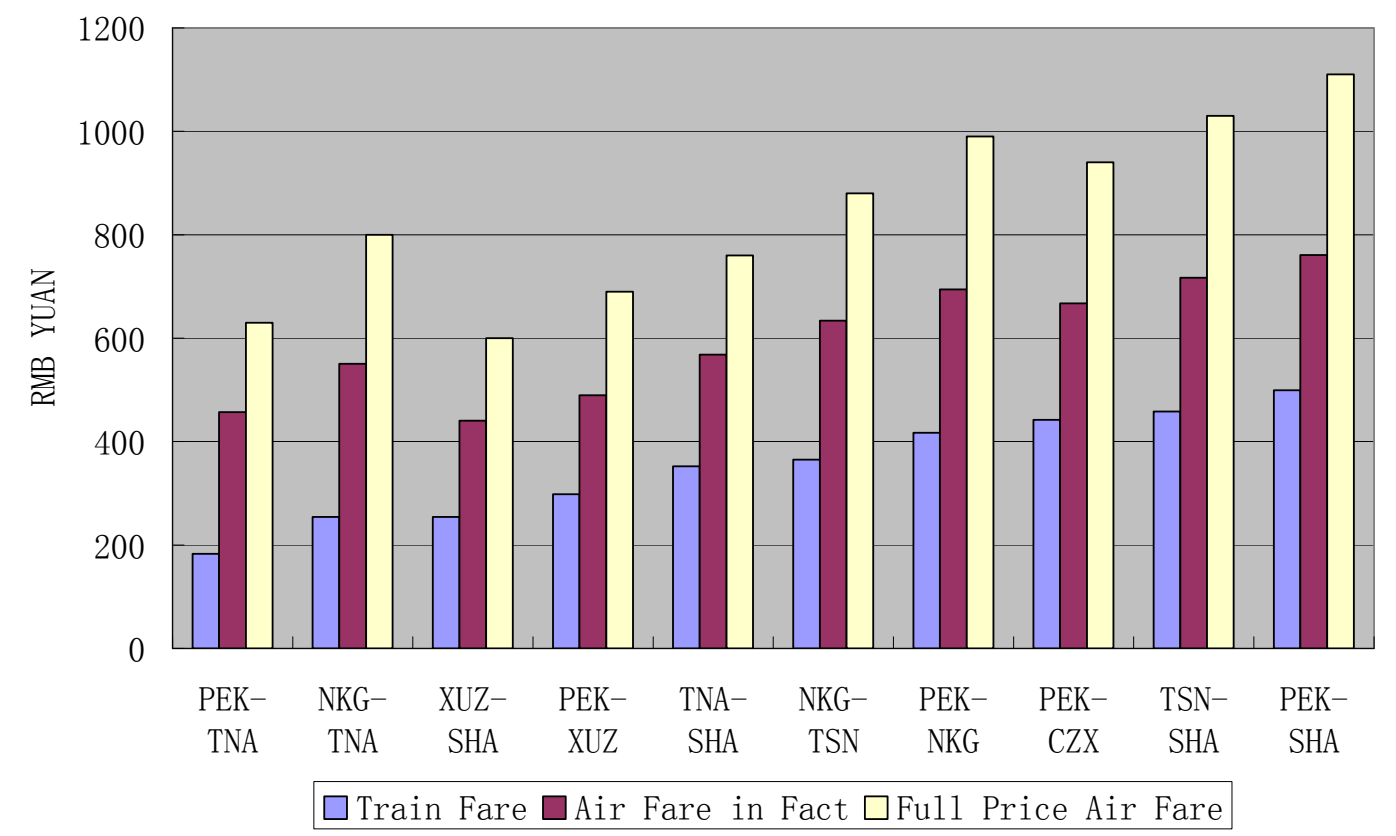

Notes:

1. Short-distance railway fares for soft seats and long-distant railway fares for soft sleeping berth.

2. Actual airfares are measured by average discount.

3. Full fare tickets base on the benchmark fares announced by the CAAC.

Source: CASTC. 


\section{COMPETITI ON BETWEEN CI VI L AVI ATI ON AND HI GH-SPEED RAI LWAY}

Though the fifth speed-up of railways did not affect the operation of airlines, the data implied that the sixth speed-up of railways in 2007 has obviously impacted on the passenger volume and revenue of airlines in certain routes, especially on the route of Beijing-Jinan. Benefit from the sixth speed-up in April 2007, the runtime of the train between Beijing and Jinan has shortened to 3.4 hours from 4.1 hours with an average speed of $146 \mathrm{~km} / \mathrm{hr}$, so the carriage capacity of the train has increased obviously. Responding to this, the numbers of air passenger transport decreased $6 \%$ with $5.7 \%$ drop in passenger load and $16 \%$ drop in revenue per seat$\mathrm{km}$ (see Table 2). It can be predicted that profound impact will occur inevitably to short-mid distance air transportation if further speed-up of railway is adopted.

Table 2: airline data on route PEK-TNA

\begin{tabular}{|c|c|c|c|c|c|}
\hline Year & $\begin{array}{c}\text { Passengers } \\
\text { (thousand) }\end{array}$ & $\begin{array}{c}\text { Seats } \\
\text { (thousand) }\end{array}$ & $\begin{array}{c}\text { Passenger } \\
\text { load Fact }\end{array}$ & $\begin{array}{c}\text { Daily } \\
\text { Frequency }\end{array}$ & $\begin{array}{c}\text { Revenue per } \\
\text { seat-km } \\
\text { (RMB Yuan) }\end{array}$ \\
\hline 2006 & 425 & 562 & $75.6 \%$ & 10.6 & 1.22 \\
\hline 2007 & 400 & 572 & $69.9 \%$ & 10.4 & 1.03 \\
\hline Rate & $-6 \%$ & $2 \%$ & $-5.7 \%$ & $-2 \%$ & $-16 \%$ \\
\hline
\end{tabular}

Source: CASTC.

It is reported that the runtime of trains between cities in Beijing-Shanghai railway corridor will sharp shorten after the high-speed railway being open to traffic. Beijing-Shanghai runtime will be reduced to 5 hours to meet its designed expectation while that of Beijing-Jinan and NanjingJinan will be reduced to 2 hours. In addition, no soft sleeping berth but soft seats will be placed on the train and the expected fares of soft seats will be not less than the current soft seat fares of D-letter motor train set. Taking public welfare into consideration, the railway administration has no reason to raise the fares by much, and so it is expected that the train fare will possibly increase $10 \%$ of $D$-letter prices at most in our forecast (see Table 3 ). 
Table 3: Travel time and fares of current train and high-speed Train in forecast

\begin{tabular}{|c|c|c|c|c|c|}
\hline & $\begin{array}{c}\text { Current Travel } \\
\text { Time By Train } \\
\text { (Hours) }\end{array}$ & $\begin{array}{c}\text { Travel Time } \\
\text { by High-speed } \\
\text { Train (Hours) }\end{array}$ & $\begin{array}{c}\text { Current Train } \\
\text { Fare } \\
\text { (RMB Yuan) }\end{array}$ & \multicolumn{2}{|c|}{$\begin{array}{c}\text { High-Speed } \\
\text { Train Fare } \\
\text { (RMB Yuan) }\end{array}$} \\
\cline { 5 - 7 } & 3.4 & 2 & 183 & 183 & 201 \\
\hline PEK-TNA & 5.1 & 2 & 254 & 254 & 279 \\
\hline NKG-TNA & 4.3 & 2.5 & $254^{*}$ & 254 & 279 \\
\hline XUZ-SHA & 6.5 & 3 & $298^{*}$ & 302 & 332 \\
\hline PEK-XUZ & 6.9 & 3.5 & $365^{*}$ & 379 & 417 \\
\hline NKG-TSN & 7.2 & 3.5 & $352^{*}$ & 359 & 395 \\
\hline TNA-SHA & 8 & 4 & $417^{*}$ & 430 & 473 \\
\hline PEK-NKG & 8.9 & 4.5 & $458^{*}$ & 487 & 536 \\
\hline TSN-SHA & 10.5 & 4.5 & $458^{*}$ & 495 & 545 \\
\hline PEK-WUX & 11.4 & 5 & $442^{*}$ & 468 & 515 \\
\hline PEK-CZX & 10 & 5 & $499^{*}$ & 542 & 600 \\
\hline PEK-SHA & & & & \\
\hline
\end{tabular}

Note: * refers to fares for soft sleeping berth and the others are for soft seats.

After the operation of high-speed railway, the advantage of transportation time of civil aviation is less obvious than before (see Chart 4). It takes passengers only 1 more hours to have a short-distance travel by high-speed trains than by airplanes in Beijing-Jinan, Nanjing-Jinan, Xuzhou-Shanghai and Beijing-Xuzhou routes. The saving time by air will be rather slender than by high-speed train if taking time in check-in and luggage claim after arriving. Based on the relevant researches, traveling by high-speed trains will faster than by planes in a range of 800 $\mathrm{km}$ distance if door-to-door travel time is taken into consideration (See Gleave 2004). Nevertheless, the civil aviation will still keep its dominance in long distance travel between cities, for instant, Beijing and Shanghai. Though it can merely save passengers 3 hours by airplanes than by high-speed trains, it is certain that many passengers would rather take the saved 3 hours for staying with family and for more rest. 
Figure 4: Comparison on transportation time between the civil aviation and the railway service in 11 city pairs

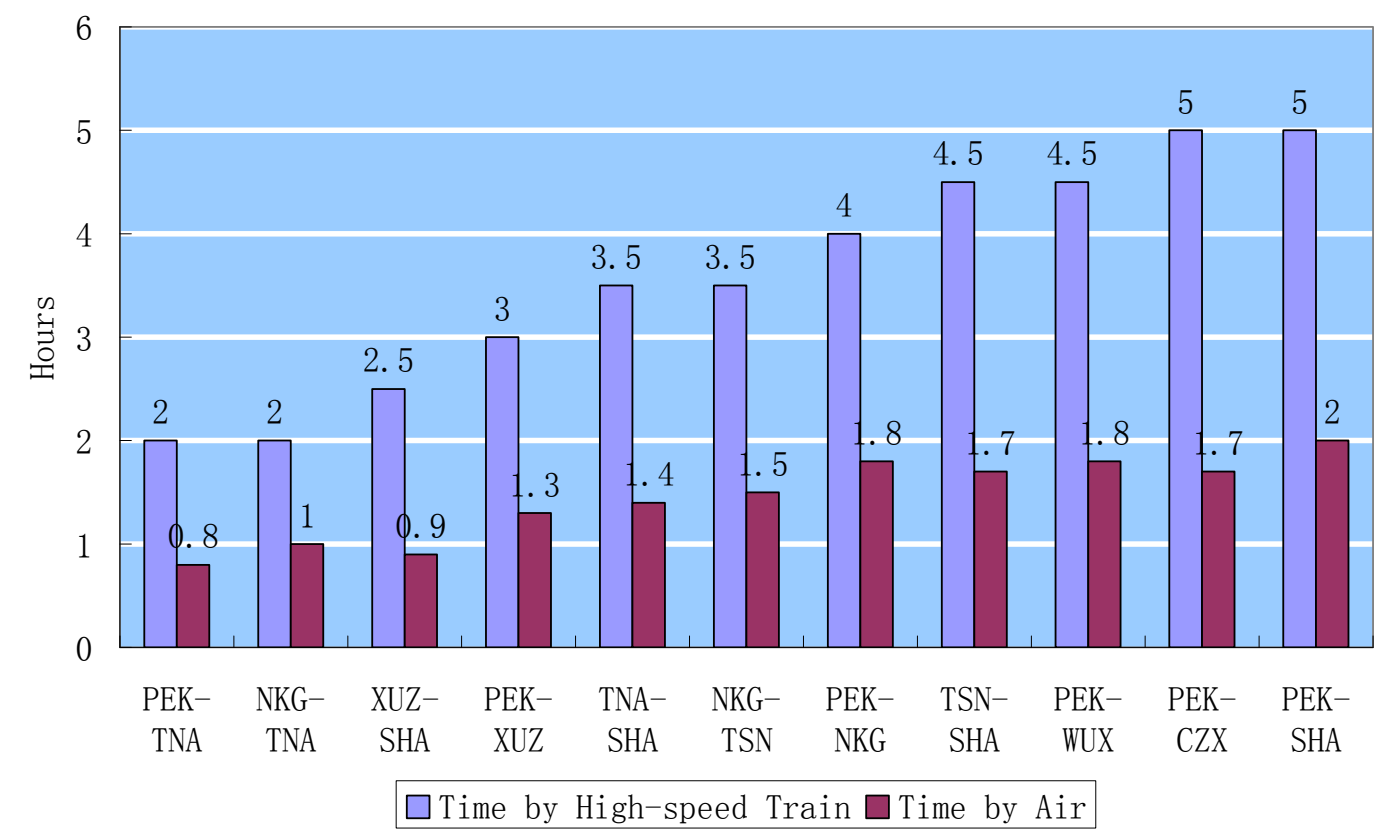

On the other hand, the high-speed railway still holds a fare advantage if compared with the average current airfare discounts. No matter which fixed prices--the high one or the lower one-is taken by the high-speed railway system, the airfares will be two times or more expensive than the high-speed train fares applied to Beijing-Jinan and Nanjing-J inan passenger service. For long-mid distance travel, there are no competitive fares with high-speed trains if higher fares were carried out by the high-speed train's administrator, the airfares will be less than 1.5 times of the train fares. Furthermore, the airlines can adjust the price flexibly to fit the market demand of the transportation. Therefore, the future price fixed by the high-speed train service will bring significant impact on relevant transportation markets and will determine the competitive pattern in which the civil aviation and the high-speed railway service are involved.

Time value is also a key factor unquestionably when the passengers make their decisions on by what they will travel. Both business passengers and leisure tourist passengers have their opportunity costs of time increased accompanying economic growth, so that they are more sensitive to travel time. It is forecasted that the per capita GDP of Beijing, Shanghai, Wuxi are higher, while that of Xuzhou, about one third of that of Shanghai, is still lower. The reason why this paper does not measure the paying ability of passengers in terms of commonly-used per 
capita disposable income is that the spending on travel for business purpose is not paid by individuals. Therefore, it is more accurate to consider the average level of productivity in terms of unit-hour in the society than per capita disposable income.

\section{AI R-RAI L COMPETITI ON MODEL}

If aviation and railway are supposed to be the only two modes for transportation, then a Logit model could be adopted to analyze the competition between the railway services and the airlines, considering that randomization exists in choosing the travel tools by the passengers (See Shan 1998, and Liu 2003). The model is represented by formulas as follow:

$$
P_{a}=\frac{\exp \left(-V_{a}\right)}{\exp \left(-V_{a}\right)+\exp \left(-V_{r}\right)}, \quad P_{r}=\frac{\exp \left(-V_{r}\right)}{\exp \left(-V_{a}\right)+\exp \left(-V_{r}\right)}
$$

In above formulas, $P_{a}$ and $P_{r}$ refer to the share rates of passenger carriage by aviation and railway respectively, and $V_{a}$ and $V_{r}$ refer to the generalized travel expense of air passengers and railway passengers respectively.

Definition: Generalized travel expense of air passengers and railway passengers represented as:

$$
V_{a}=f\left(F_{a}, T_{a}\right), \quad V_{r}=f\left(F_{r}, T_{r}\right)
$$

In above formulas, $F_{a}$ and $F_{r}$ refer to the passengers transport costs of airlines and railways respectively, $T_{a}$ and $T_{r}$ refer to the door-to-door travel time by air and railway respectively.

With the difference of passenger structures and affordability among cities, the average time values for passengers are also different. And this has a close connection with the average local level of productivity in terms of unit-hour like the analysis above-mentioned, so the generalized travel expense of air passengers and railway passengers is formulated here as: .

$$
V_{a}=\alpha_{1} \lambda F_{a}+\alpha_{2} \lambda g T_{a}
$$




$$
V_{r}=\alpha_{1} \lambda F_{r}+\alpha_{2} \lambda g T_{r}
$$

In the above formulas, $g$ refers to average local level of productivity in terms of unit-hour, $\alpha_{1}$ and $\alpha_{2}$ refer to a relevant phased weight coefficient in $\alpha_{1}+\alpha_{2}=1$, and $\lambda$ refers to the correction coefficient for transportation options with a range from 0 to 1 .

Definition: average local level of productivity in terms of unit-hour represented as:

$$
g=G / h
$$

In this formula, $G$ refers to current year local per capita GDP and $h$ refers to annual per capita working hours.

Simultaneous equations:

$$
\begin{aligned}
& P_{a}=\frac{1}{1+\exp \left[\alpha_{1} \lambda\left(F_{a}-F_{r}\right)+\alpha_{1} \lambda g\left(T_{a}-T_{r}\right)\right]} \\
& P_{r}=\frac{1}{1+\exp \left[\alpha_{1} \lambda\left(F_{r}-F_{a}\right)+\alpha_{1} \lambda g\left(T_{r}-T_{a}\right)\right]}
\end{aligned}
$$

In regard to the difference of passenger structures in different city pairs and passenger's preference in travel time and fares, say, the difference of share coefficients $\alpha_{1}$ and $\alpha_{2}$, the statistic data investigation and chronological statistic data which is available are a must to obtain the share coefficients for city pairs.

This paper just estimates the competition in passenger transportation for Beijing-Shanghai and Beijing-J inan routes if the high-speed railway will operate in 2010. In route Beijing-Shanghai, on condition of average $30 \%$ discount airfares from all airlines, $40 \%$ of passengers will take trains and the rest take planes if the train service sets a lower price for high-speed train fairs, while $30 \%$ of passengers will travel by trains and the rest by air if high price is set. Therefore, 
combining the pricing of high-speed trains with responding airfare policies will have an important effect on the model of passengers' travel in this route.

In route Beijing-Jinan, on condition of average $25 \%$ discount airfares from all airlines, $86 \%$ of passengers will take trains and $14 \%$ of them take planes if the train service sets a lower price for high-speed train fairs, while $85 \%$ of passengers will travel by trains and $15 \%$ of them by air if high price is set. Therefore, combining the pricing of high-speed trains with responding airfare policies will have a weak effect on the model of passengers' travel in this route.

\section{MEETI NG THE CHALLENGES FROM HI GH-SPEED RAI LWAY}

The China's civil aviation industry plans to obtain $20 \%$ of passenger transport market calculated by passenger turnover volume by 2020. To achieve this goal and to deal with the challenges which are brought by the high-speed railway, the civil aviation must take necessary actions to guarantee its market share and economic benefits. On one hand, it needs to better use its floating airfare mechanism based on subdivision of passenger groups and take flexible fare policies to guarantee its revenue and get hold of the passengers who might turn toward highspeed trains by satisfying the needs of different passenger groups. On the other hand, it needs to reduce the passengers' door-to-door travel time by optimizing the passenger flow by the combination of the airlines, airports and air control bureau (Liu 2007). Furthermore, increasing flight frequency, improving flights punctuality and services need to be concerned more carefully as they are becoming more and more important.

Better utilization of fare policies is the most important measure to acquire more markets share for all airlines. Firstly, the airlines should let the passengers understand that air travel is not an extravagant spending, because the loyal railway passengers will not care about the airfares even though they are less expensive than train fares in some intercity routes in a slack season for traveling due to their intrinsic concept that air travel is an expensive consumption. Thus, it is necessary to have the passengers, especially those who are sensitive to the fares, aware the possibility to compare the airfares with the high-speed train fares before making a decision on how to travel, particularly in the early days of high-speed railway operation. Secondly, the adoptions of different fare policies which aim at the needs of different characters of air passenger are important strategies for airlines. A current diversifying pricing management 
method is used popularly by airlines which price-sensitive passengers are attracted by discount air tickets to increase the passenger load while those who care little about the fares are sold full fare tickets and business-class tickets. If there are more low-cost airlines operating in the future, it is possible to shape a pattern in which the airlines for trunk line travel provide upscale services mainly to high-end passengers and the low-cost airlines compete with the high-speed train services to scramble for the rest passengers. Most importantly, the precondition for airfare decrease is to improve the management and reduce the operation cost, and only with this the airlines can get the space to offer low fare air tickets.

Reducing the door-to-door air travel time for passengers as much as possible is another important measure to guarantee the market share for airlines. Firstly, it is important to improve airport accessibility to reduce travel time of air passengers. Secondly, to set up "Air Express" in golden routes with more passenger movements, which offer more service promises including any-time ticket endorsement convenience and less time in ticket reservation, check-in, security check and luggage claim. Promoted by the CAAC, five airlines including Air China and China Eastern Airlines worked together to set up a 'Beijing-Shanghai Express' in 2007 to ensure at least one flight taking off every half an hour, the check-in being stopped 15 minutes prior to flight taking off and ticket endorsement at any time. This measure effectively consolidates the dominant position of the civil aviation in intercity transportation markets in route BeijingShanghai. Thirdly, promoting passengers put more trust in the airlines by punctuality improvement. After the high-speed railway operating, the fact is that travel time by trains is shortened greatly. It implies that taking a delayed flight normally occupy more time than taking a high-speed train, which is a competitive pressure that the airlines have to deal with. At last, increasing more flights to help passengers decide their flight time more flexibly and reduce waiting time between every two flights in some level. The measure that all airlines increase the flight frequency will doubtlessly enhance its competitive capability to a great extent for the civil aviation, especially in the routes with less numbers of nonstop trains everyday, for example, route Beijing-Changzhou and route Beijing-Wuxi. 


\section{CONCLUSION}

Beijing-Shanghai high-speed railway project will indeed be a severe challenge to airlines in the future. The impact that the project will have on the civil aviation is far more exceed that the six prior railway speed-ups had. In mid- long distance travel, passengers will be more difficult to decide how they travel when the high-speed railway is put into service because of the high possibility of alternative between high-speed railway service and civil aviation. Therefore, the fare policies that directly affect the passengers' choices and the competition pattern between civil aviation and high-speed railway. In short distance routes, the airlines will not lose all of their passengers. Along with the high-speed development in Chinese national economy, a subtle change will happen in the competition between the civil aviation and the high-speed railway service. The airlines will be able to take advantage of the increasing passenger concern on travel time to gain more market share or increase gradually airfares to earn more.

To meet more and more violent competition, it needs the airlines, airports and the Air Traffic Control Bureau together to ensure the competitive advantage in travel time by improving the time management in the flights arrangement. On the other hand, the airlines initiatives to apply flexible airfare mechanism will be an important factor that has an impact on the air-rail competition pattern when a fixed pricing mechanism is still adopted by the railway service.

\section{References}

- CIECC, (2006), Beijing-Shanghai High-speed Railway Feasibility Evaluation Report, CIECC, 2006.

- Fu, L.J . (2005), 'The Demonstration Analysis on the Effects of Creating the Train Velocity to Civil Aviation's Passenger Traffic', Journal of Zhengzhou Aviation Management Institute, Vol. 23 No.1 (March) pp.29-32.

- Gleave, S.D. (2004), High Speed Rail: International comparisons final report. www.steerdaviesgleave.com

- Liu, D.P. (2003), 'Research on the Approach to the Travel Time Value Analysis', Journal of East China Economic Management, Vol.17, No.4 (August) pp155-156. 
- Liu, Y.T., Li, Y.H. and Weng, L. (2007), 'The Impact of the Sixth Speed Increase of Railway and Recommendations to Civil Aviation Industry', China Civil Aviation, Vol.82, (October 2007) pp.30-32.

- Shan, D.F., Zhu, J.S. and Jia, Y.H. (1998), 'Study on Beijing-Shanghai High-speed Railway and Civil Aviation Passenger Distribution Model', Railway Operating Tech, Vol 14, No.2, (April) pp.47-51. 